\title{
Fault Diagnosis of PMSG Wind Power Generation System Based on LMD and MSE
}

\author{
Hao Duan, Ming Lu $\mathbb{D}^{\text {, }}$, Yongteng Sun, Jinyu Wang, Cheng Wang, and Zuguo Chen \\ School of Information and Electrical Engineering, Hunan University of Science and Technology, Xiang Tan 411201, China \\ Correspondence should be addressed to Ming Lu; mlu@hnust.edu.cn
}

Received 21 May 2020; Revised 1 July 2020; Accepted 11 July 2020; Published 28 July 2020

Guest Editor: Kailong Liu

Copyright (c) 2020 Hao Duan et al. This is an open access article distributed under the Creative Commons Attribution License, which permits unrestricted use, distribution, and reproduction in any medium, provided the original work is properly cited.

\begin{abstract}
After fault occurs, the fault diagnosis of wind turbine system is required accurately and quickly. This paper presents a fault diagnostic method for open-circuit faults in the converter of permanent magnet synchronous generator drive for the wind turbine. To avoid misjudgement or missed judgement caused by improper thresholds, the proposed method applies Local Mean Decomposition and Multiscale Entropy into the converter of wind power system fault diagnosis for the first time. This paper uses a novel multiclass support vector machine to classify the faults hardly diagnosed by other methods. Simulation results show that the method has the characteristics of high adaptability, high accuracy, and less diagnosis time.
\end{abstract}

\section{Introduction}

The development of control strategies and detection of energy storage equipment bring considerable progress for the optimization and control of complex renewable energy systems [1-13]. In this field, wind turbines with permanent magnet synchronous generators (PMSGs) have become popular due to numerous advantages, such as gearbox-free, simple converter topology, and high efficiency at low wind speed, noise, and maintenance cost [14-19]. Wind power generation systems of PMSG are equipped with back-toback full-scale power converter to improve the quality of transmitted power to the power grid [20]. However, the wind turbines usually operate in high temperatures and stressful environments, thereby weakening the converter of the variable-speed constant-frequency wind turbine [21]. Converter faults can be divided into short- and open-circuit faults [22, 23]. The occurrence of short-circuit fault is considerably rapid, easily triggering the protection mechanism of the system; thus, the fault can be quickly detected [24]. However, open-circuit (OC) faults do not generate a large current and have difficulty to trigger the protection mechanism [25]. Thus, immediately detecting these faults is difficult. OC faults may also cause potential secondary faults, which lead to the overall damage of the converter, ultimately, causing the shutdown of the wind turbine [21]. This phenomenon will decrease the reliability and stability of the system.

When power switches in different positions of the converter occurs OC faults, the voltage and current variables of the converter will show different fault characteristics. So, the open switch fault diagnosis of the converter can be performed by the analysis of voltage or current [26-31]. With the advantages of using readily available quantities from the main control system without the additional sensors, fault diagnosis based on the current signal can be considered a class of feasible method because it is independent of either the system parameters or the control strategy and do not require additional sensors [32]. Abramik et al. [33] proposed a method based on the calculation of the normalised current average values of the fundamental and DC components of stator currents in each current cycle. Jlassi et al. [28] normalised the effective value of currents based on their average value and used the normalised value for the open-circuit fault feature extraction. However, this method cannot diagnose two insulated gate bipolar transistor (IGBT) OC faults on the same bridge simultaneously. Estima et al. [34] utilised the normalised current average 
absolute value instead of the average value as the normalised variable for feature extraction. Khomfoi et al. [35] proposed a normalisation method based on the current instantaneous value, using Park's vector modulus as the normalisation variable. Furthermore, the probability density function control strategy can be used for fault diagnosis and by designing appropriate controllers [36]. Yao et al. [37] proposed an iterative learning observer-based algorithm for fault diagnosis, and the method can be used in fault diagnosis of the constant fault, slow-varying fault, and fastvarying fault, but the control strategy is complicated. Yin et al. [38] proposed a RBFNN-based minimum entropy filter. The advantage of the method is parameters of the controller can be identified by data and decreases the difficulty in the fault diagnosis design, but stability of the model should be further analysed. However, in numerous existing methods, the threshold is fixed and highly dependent on the prior knowledge of the system. Thus, the selection of threshold seriously affects the reliability of fault diagnosis when the operating conditions are changed. A data-driven fault diagnosis strategy of 21 kinds of OC faults wind power converters is proposed in this paper based on the local mean decomposition (LMD) and multiscale entropy (MSE). This strategy can avoid the misjudgement or missed judgement caused by improper threshold selection and has high accuracy in the diagnosis process.

\section{System and Fault Description}

System configuration of the permanent magnet synchronous generator (PMSG) with variable-speed constant-frequency wind turbine is the current mainstream of wind power generation systems due to the following advantages: gearbox-free, simple converter topology, and high efficiency at low wind speed situation. The topology of a PMSG wind power system is shown in Figure 1.

The power converter usually adopts a converter combination of a back-to-back structure. The converter near the rotor side is called a rotor-side converter. This converter adjusts the currents of $d q$ axes to track the maximum wind energy, achieves the variable speed with constant frequency, and improves the operating efficiency of the power generation system. The converter near the grid side is called a gridside converter. This converter maintains the DC-side voltage constant and prevents grid-side current harmonics. Both sides of the converter have the same structure with a space vector pulse width modulation (SVPWM) strategy.

2.1. Wind Turbine Model. The wind turbine (WT) system is a kind of nonlinear due to the stochastic characteristics of natural wind and the aerodynamic characteristics of WT $[39,40]$. The disturbance can be divided as internal and external disturbance. The internal mainly comes from parameter variations, control couplings, current harmonics, modeling errors, and nonlinear dynamics of the plant. The external disturbance mainly comes from wind speed change, torsional vibration, wind stream dissymmetry, etc [41]. The model of the WT is given by the following equation:

$$
\begin{aligned}
P_{m} & =\frac{1}{2} \rho \pi R^{2} v^{3} C_{p}(\lambda, \beta)=\omega_{m}\left(J \frac{d \omega_{m}}{d t}+f \omega_{m}+T_{e}\right), \\
T_{m} & =\frac{P_{m}}{\omega_{m}}=\frac{1}{2} \rho \pi R^{5} \frac{C_{p}(\lambda, \beta)}{\lambda^{3}} \omega_{m}^{2}, \\
T_{e} & =\frac{5}{2} n_{p} \psi i_{q}, \\
\lambda & =\frac{\omega_{m} R}{v},
\end{aligned}
$$

where $P_{m}$ is the power absorbed by the wind wheel, $T_{m}$ is the mechanical torque, $\rho$ is the air density, $R$ is the radius of wind wheel, $v$ is the wind speed, $C_{p}(\lambda, \beta)$ is the power coefficient, $\omega_{m}$ is the rotor speed, $J$ is the moment of inertia, $f$ is the viscous damping coefficient, $T_{e}$ is the electromagnetic torque, $n_{p}$ is the pole pair number, $\psi$ is the flux linkage, $i_{q}$ is the $q$ axis current of $d q$ axes currents, $\lambda$ is the ratio of tip speed, and $\beta$ is the pitch angle.

The MPPT control is applied when the $v$ is smaller than the rated speed. When $v$ is greater than the rated speed, output power of the PMSG is controlled by $\beta$. In the proposed method, the $v$ is between the cut-in wind speed and the rated wind speed. Therefore, the $\beta$ is constant at $0^{\circ}$ and $C_{p}$ is only relate to $\lambda$. The nonlinear third-order polynomial equation of the $C_{p}$ characteristic is as follows [42]:

$$
C_{p}(\lambda)=a_{0}+a_{1} \lambda+a_{2} \lambda^{2}+a_{3} \lambda^{3},
$$

where $a_{0}=0.00715814, a_{1}=-0.04454063, a_{2}=0.02899277$, and $a_{3}=-0.00202519$.

2.2. Fault Description. The definition of the current Park's vector is given by the following equation:

$$
\begin{aligned}
& i_{d}=\sqrt{\frac{2}{3}} i_{a}-\frac{1}{\sqrt{6}} i_{b}-\frac{1}{\sqrt{6}} i_{c}, \\
& i_{q}=-\frac{1}{\sqrt{2}} i_{b}-\frac{1}{\sqrt{2}} i_{c},
\end{aligned}
$$

where $i_{a}, i_{b}$, and $i_{c}$ are the currents' instantaneous values.

When the OC fault occurs in the converter, the output current of the converter will distort. It will cause the electromagnetic torque ripple and further affect rotor speed control of PMSG. The current waveform of $i_{a}, i_{b}, i_{c}$ with normal system operation is shown in Figure 2(a). When OC faults occur in the converter, the waveform of the threephase current $i_{a}, i_{b}, i_{c}$ will be changed according to the position and number of the IGBT. Figures 2(b)-2(e) show that the OC fault occurs after normal system operation at $0.5 \mathrm{~s}$.

\section{Fault Diagnosis Method}

3.1. Signal Processing Based on LMD-MSE. LMD is a nonlinear and nonstationary signal analysis method. This method separates a frequency-modulated signal from an 


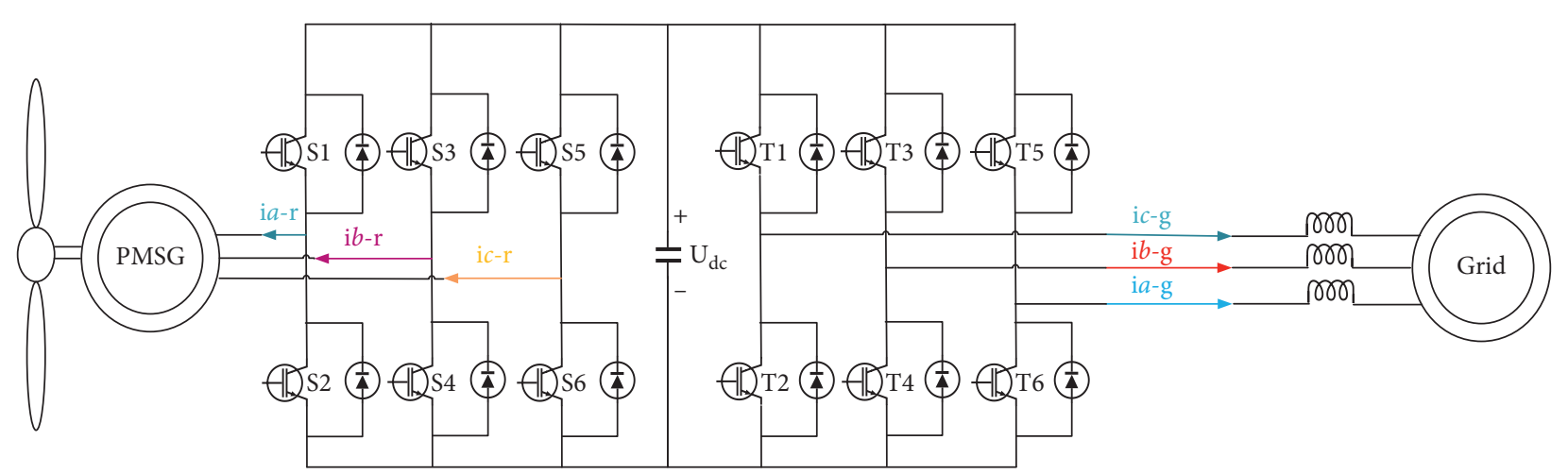

FIgURE 1: PMSG wind power generation system.
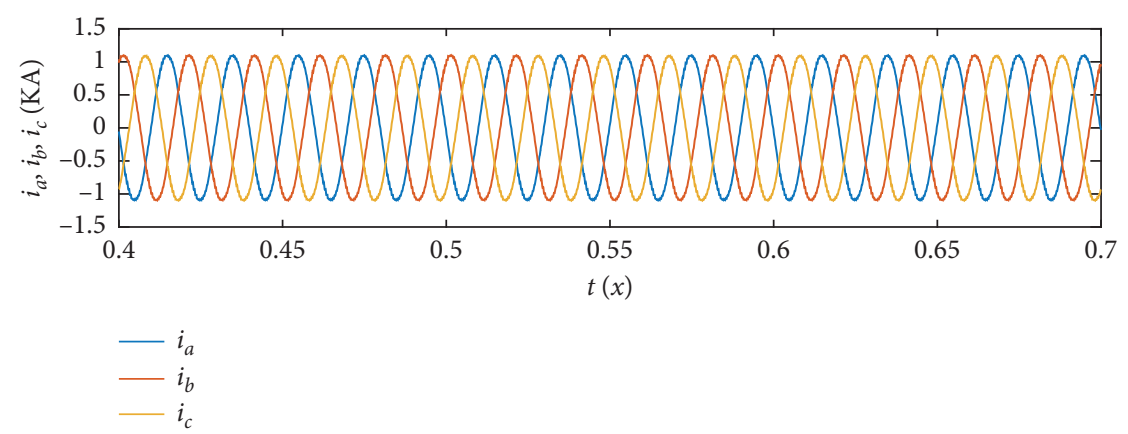

(a)

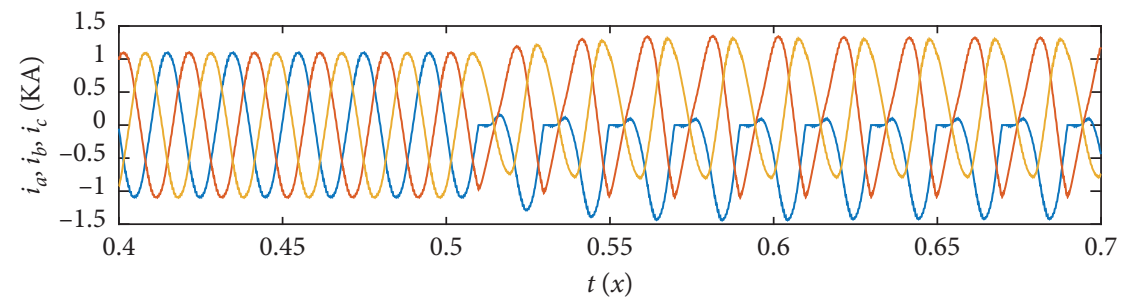

$-i_{a}$
$-i_{b}$
$-i_{c}$

(b)

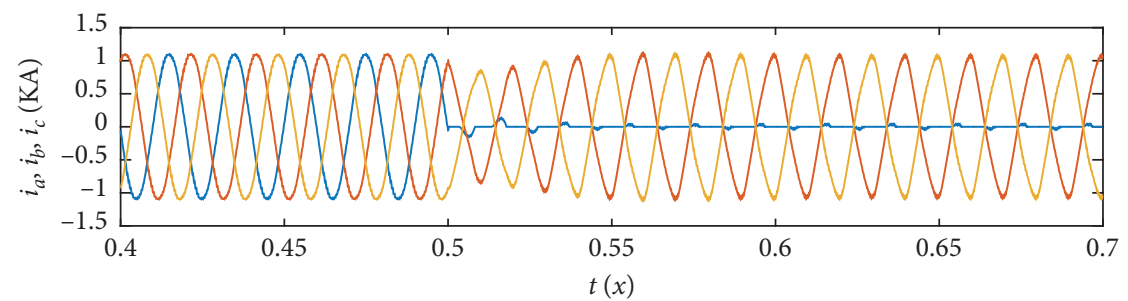

$i_{a}$
$-i_{b}$
-

(c)

FIgure 2: Continued. 


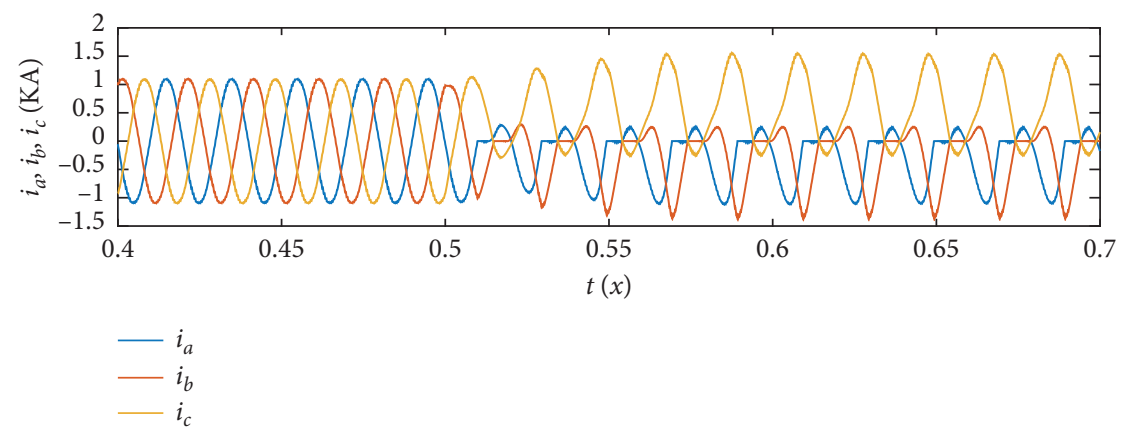

(d)

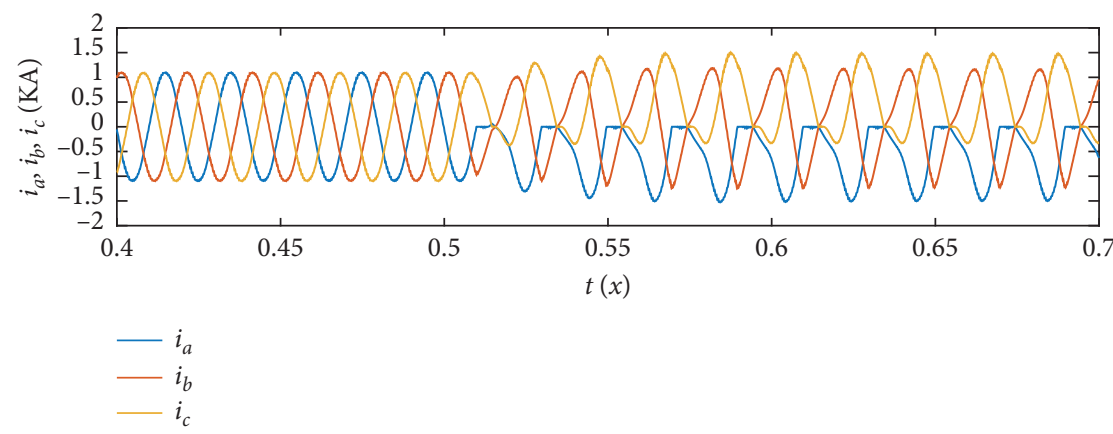

(e)

FIGURE 2: Current waveform of three currents $i_{a}, i_{b}, i_{c}$. (a) Normal state. (b) OC fault occurrence in S1. (c) OC fault occurrence in S1 and S2. (d) OC fault occurrence in S1 and S3. (e) OC fault occurrence in S1 and S6.

amplitude-modulated envelope signal and achieves a series of product function (PF) and residual components [43]. The MSE is based on sample entropy and describes the complexity of time series on multiple time scales. In the proposed method, the three-phase output current of the converter is firstly processed by LMD, and the first three PF components of each current are obtained. Then, the mean of MSE is then calculated on the basis of the statistical characteristics of the PFs. Finally, the extracted LMD-MSE information is used to describe the diagnostic features. The details of algorithm are as follows:

(1) Calculate the mean $m_{i}$ and the envelope estimate $a_{i}$ for all local extreme points $n_{i}$ of the original signal $x(t)$.

(2) Smooth $m_{i}$ and $a_{i}$, and then obtain the local mean function $m_{1}(t)$ and the envelope estimation function $a_{1}(t)$.

(3) Separate $m_{1}(t)$ from $x(t)$ to obtain the FM signal $s_{1}(t)$ :

$$
\begin{aligned}
& h_{1}(t)=x(t)-m_{1}(t), \\
& s_{1}(t)=\frac{h_{1}(t)}{a_{1}(t)} .
\end{aligned}
$$

(4) Repeat steps (1)-(3), until $a_{n}(t)$ meets the following form:

$$
\lim _{n \rightarrow \infty} a_{n}(t)=1
$$

(5) Obtain the envelope signal $a(t)$ :

$$
a(t)=\prod_{k=1}^{n} a_{k}(t)
$$

(6) Calculate PF component:

$$
P F_{1}=a(t) s_{n}(t)
$$

(7) Separate $P F_{1}$ from the original signal, obtain $u(t)$ as the new signal, and repeat (1)-(6) until $u(t)$ is monotonous.

(8) Construct the coarse-grained $y^{(s)}$ from the original series with scale factors $s(s=1,2, \ldots, N)$ for each PFs:

$$
y_{j}^{(s)}=\frac{1}{s} \sum_{i=(j-1) s+1}^{j s} x_{i} 1 \leq j \leq(N / S) .
$$

(9) Calculate the sample entropy of $y^{(s)}$.

(10) Change the scale factors and repeat steps (8)-(9). 
(11) Calculate the mean of $y^{(s)}$.

The procedure of LMD-MSE is shown in Figure 3.

3.2. Concept of RSSVM. The support vector machine (SVM) principle comes from statistical learning theory proposed by Vapnik [44]. SVM is a supervised learning method, which aims to establish an optimal hyperplane as the decision surface, to maximise the isolated edges amongst different classes. However, 21 kinds of converter OC fault types are available. Thus, numerous classifiers must be constructed, causing unsatisfactory diagnosis accuracy and slow classification speed. In the proposed method, a multiclass SVM, that is, RSSVM, can effectively reduce the number of classifiers and improve accuracy and speed.

Consider the following training dataset for the K-class problem [45]:

$$
S=\left\{\left(x_{1}, y_{1}\right),\left(x_{2}, y_{2}\right), \ldots,\left(x_{N}, y_{N}\right)\right\},
$$

where $x_{i}=\left[x_{i 1}, x_{i 2}, \cdots, x_{i n}\right]^{T}$ is the feature vector of the $i$ th sample and $y_{i} \in\{1,2, \ldots, K\}$ is the classification number. Figure 4 shows that each class can be represented by the coordinate vector of its corresponding vertex considering that any two vertices of a regular simplex are equidistant.

Matrix $V_{K \times K-1}=\left(V_{1}, V_{2}, \ldots, V_{k}\right)^{T}$ is used for $K$-class classification to denote the vertices of the regular simplex. A one-to-one mapping is also established between the vertices and classes. Thus, the training set from equation (2) $\mathrm{fd} 2 \mathrm{can}$ be rewritten as follows:

$$
S=\left\{\left(x_{1}, V_{C_{1}}\right),\left(x_{2}, V_{C_{2}}\right), \ldots,\left(x_{N}, V_{C_{N}}\right)\right\},
$$

where $C_{i}(1 \leq i \leq N)$ is the class of sample $x_{i}$, thus satisfying $c_{i} \in\{1,2, \ldots, K\}$.If the belonging of $i$ th and $k$ th is the same, then $C_{i}=C_{k}$.

For the $i$ th training sample, the output point $f(x)=$ $\left(f_{1}(x), f_{2}(x), \ldots, f_{n}(x)\right)^{T}$ in the same $(K-1)$-dimensional Euclidean space should be closer to its corresponding vertex $C_{i}$ than any other vertex by at least $\varepsilon>0$ :

$$
d\left(f\left(x_{i}\right), V_{k}\right)-d\left(f\left(x_{i}\right), V_{c_{i}}\right) \geq \varepsilon, \quad \forall k \neq c_{i} .
$$

Equation (15) can be simplified to the following form, which is linear about $f_{j}(x)$ :

$$
\sum_{j=1}^{K-1}\left(2\left(V_{c_{i}, j}-V_{k, j}\right) f_{j}\left(x_{i}\right)+V_{k, j}^{2}-V_{c_{i}, j}^{2}\right) \geq \varepsilon, \quad \forall k \neq c_{i} .
$$

Thus, the $K$-class classification problem can be solved by resolving the following optimisation problem:

$$
\begin{array}{ll}
\min _{f_{1}, f_{2}, \ldots, f_{K-1}} & \sum_{i=1}^{N} \sum_{k \neq C_{i}} \xi_{i, k} \\
\text { s.t. } & \sum_{i=1}^{N}\left(2\left(V_{c_{i}, j}-V_{k, j}\right) f_{j}\left(x_{i}\right)+V_{k, j}^{2}-V_{c i, j}^{2}\right) \geq \varepsilon-\xi_{i, k}, \quad \forall k \neq c_{i},
\end{array}
$$

where $\xi_{i, k} \geq 0$ is a slack variable.

Linear RSSVM for each $f_{j}(x)$ has the following form:

$$
f_{j}(x)=w_{j}^{T} x+b_{j} .
$$

Then, the optimisation problem (17) can be rewritten as follows:

$$
\begin{array}{ll}
\min _{w, b} & \sum_{j=1}^{K-1} \frac{1}{2}\left(w_{j}^{T} w_{j}+b_{j}^{2}\right)+C \sum_{i=1}^{N} \sum_{k \neq C_{i}} \xi_{i, k} \\
\text { s.t. } & \sum_{j=1}^{K-1}\left(2\left(V_{c_{i}, j}-V_{k, j}\right)\left(w_{j}^{T} x+b_{j}\right)+V_{k, j}^{2}-V_{c_{i}, j}^{2}\right) \geq \varepsilon-\xi_{i, k},(i=1,2, \ldots, N) \\
& \xi_{i, k} \geq 0,(i=1,2, \ldots, N),
\end{array}
$$




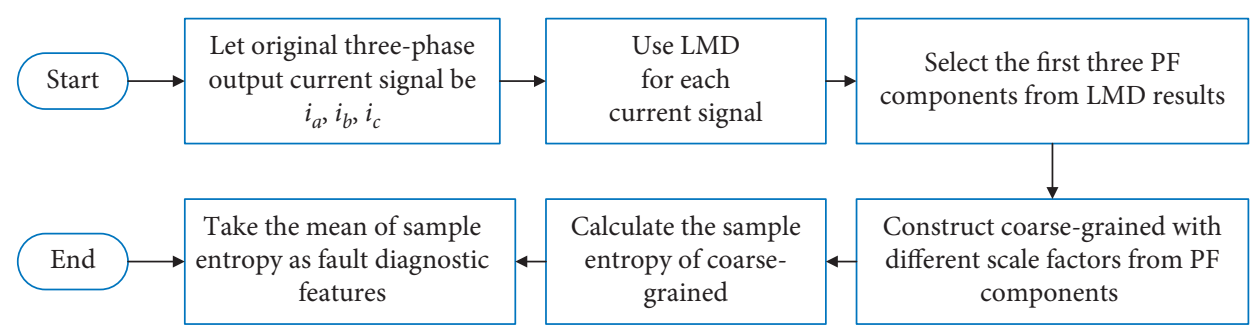

FIGURE 3: Process of LMD-MSE.

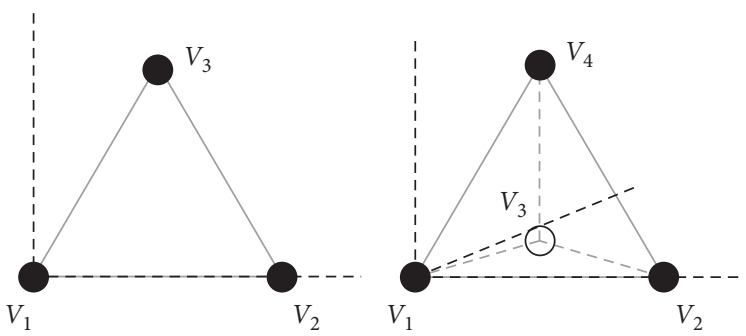

FIgURE 4: Representation of multiple classes.

TABle 1: Main parameters of PMSG.

Parameter

$$
\begin{aligned}
L(w, b, \alpha, \beta, \xi)= & \sum_{j=1}^{K-1} \frac{1}{2}\left(w_{j}^{T} w_{j}+b_{j}^{2}\right)+C \sum_{i=1}^{N} \sum_{k \neq C_{i}} \xi_{i, k} \\
& -\sum_{i=1}^{N} \sum_{k \neq C_{i}} \alpha_{i, k}\left(\sum_{j=1}^{K-1}\left(2\left(V_{c_{i}, j}-V_{k, j}\right)\left(w_{j}^{T} x+b_{j}\right)+V_{k, j}^{2}-V_{c_{i}, j}^{2}\right)-\varepsilon+\xi_{i, k}\right)-\sum_{i=1}^{N} \sum_{k \neq C_{i}} \beta_{i, k} \xi_{i, k} .
\end{aligned}
$$

Using the Karush-Kuhn-Tucker (KKT) and the following denotation,

$$
\begin{aligned}
\alpha_{i}= & \left(\alpha_{i, 1}, \ldots \alpha_{i, c_{i}-1}, \alpha_{i, c_{i}+1}, \ldots, \alpha_{i, k}\right)^{T}, \\
\widehat{\alpha}= & \left(\alpha_{1}^{T}, \alpha_{2}^{T}, \ldots, \alpha_{N}^{T}\right), \\
E_{i, j}= & 2\left(V_{c_{i}, j}-V_{1, j}, \ldots, V_{c_{i}, j}-V_{c_{i}-1, j}, V_{c_{i}, j}\right. \\
& \left.-V_{c_{i}+1, j}, \ldots, V_{c_{i}, j}-V_{k, j}\right)^{T},
\end{aligned}
$$

$$
\begin{aligned}
\widehat{E}_{j}= & \left\{\begin{array}{ccc}
E_{1, j} & \cdots & 0 \\
\vdots & \ddots & \vdots \\
0 & \cdots & E_{N, j}
\end{array}\right\}, \\
F_{i, j}= & \left(V_{c_{i}, j}^{2}-V_{1, j}^{2}, \ldots, V_{c_{i}, j}^{2}-V_{c_{i}-1, j}^{2}, V_{c_{i}, j}^{2},\right. \\
& \left.-V_{c_{i}+1, j}^{2}, \ldots, V_{c_{i}, j}^{2}-V_{k, j}^{2}\right)^{T} \\
\widehat{F}_{j}= & \left(F_{1}^{T}, F_{2}^{T}, \ldots, F_{N}^{T}\right),
\end{aligned}
$$




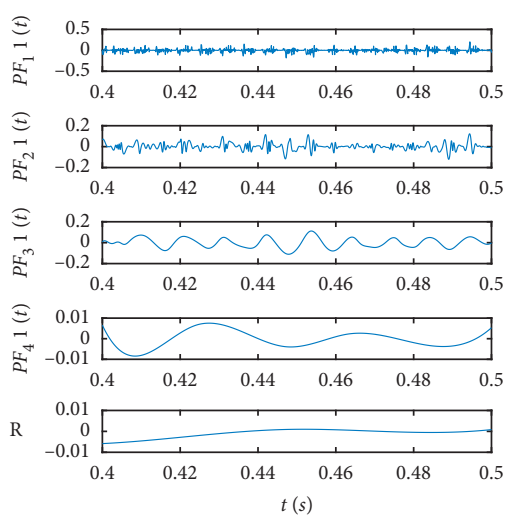

(a)

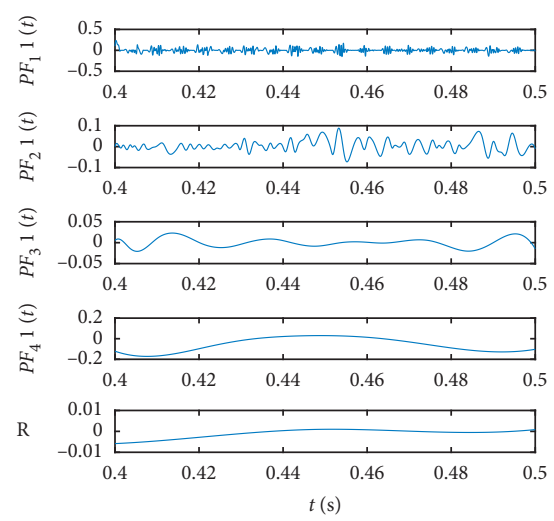

(b)

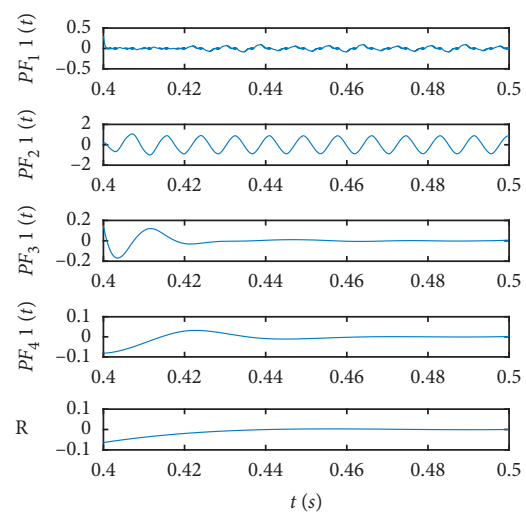

(c)

FIgURE 5: LMD decomposition of OC fault occurred in S1: (a) $\mathbf{i}_{a}$, (b) $\mathbf{i}_{\mathbf{b}}$, and (c) $\mathbf{i}_{\mathbf{c}}$.

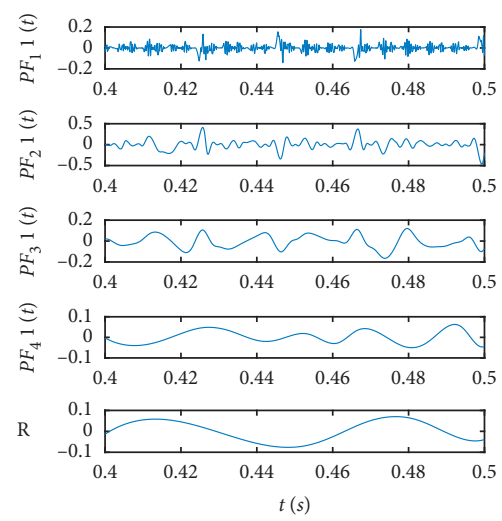

(a)

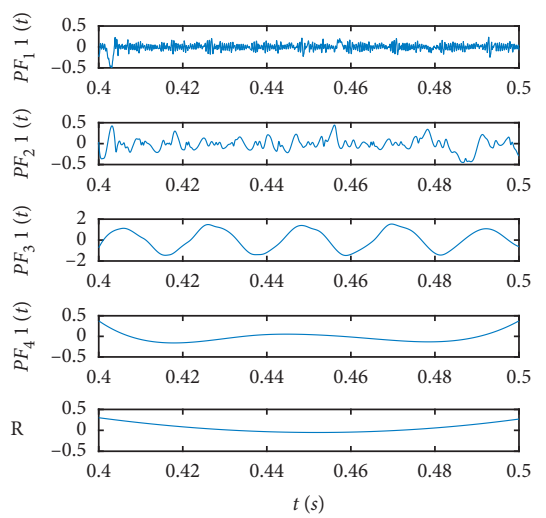

(b)

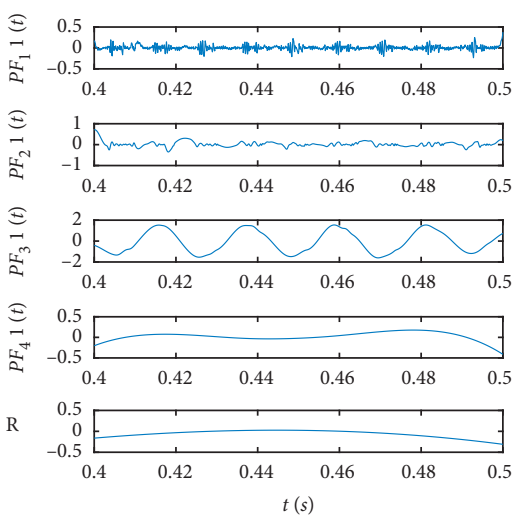

(c)

FIgURE 6: LMD decomposition of OC fault occurred in S1 and S2: (a) $\mathbf{i}_{a}$, (b) $\mathbf{i}_{\mathbf{b}}$, and (c) $\mathbf{i}_{\mathbf{c}}$.

the dual problem of optimisation problem (19) can be rewritten as follows:

$$
\begin{array}{ll}
\min _{\widehat{\alpha}} & \frac{1}{2} \widehat{\alpha}^{T}\left(\sum_{j=1}^{K-1} \widehat{E}_{j}\left(A A^{T}+e e^{T}\right) E_{j}^{T}\right) \widehat{\alpha}+T \widehat{\alpha}^{T} \sum_{i=1}^{k-1}\left(\widehat{F}_{j}+\varepsilon e\right) \\
\text { s.t. } \quad 0 \leq \widehat{\alpha} \leq C e,
\end{array}
$$

where $e$ denotes vector $(1,1, \ldots, 1)^{T}$ with appropriate dimensionalities.

For nonlinear situation, a kernel function is also used to map divisible data in low- to high-dimensional spaces linearly:

$$
K\left(x, x^{\prime}\right)=\phi(x) \cdot \phi\left(x^{\prime}\right) .
$$

The RBF kernel function is used in this paper as a kernel function due to its excellent performance in practical usage.

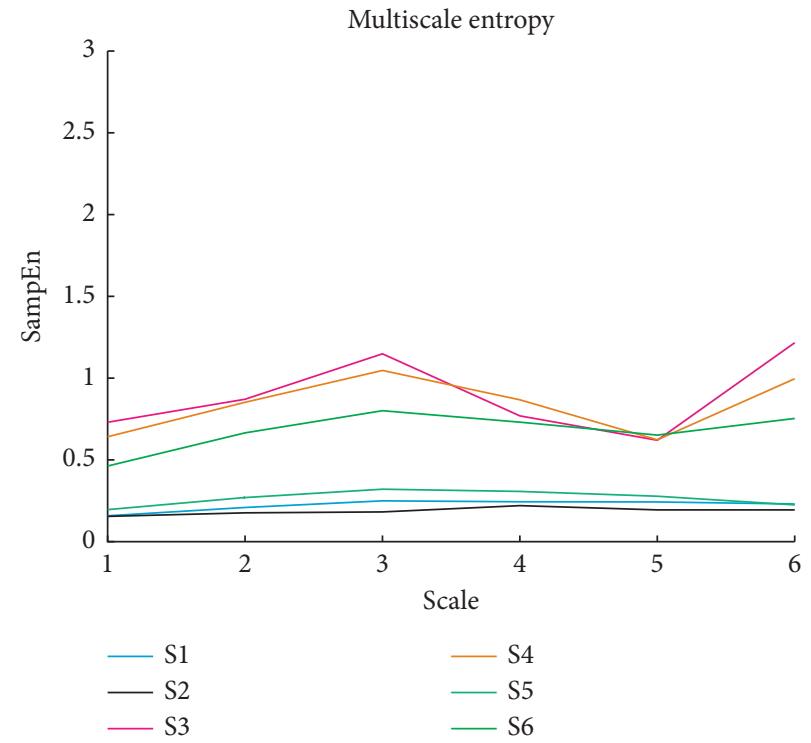

FIgURE 7: Multiscale entropy of OC fault occurred in one IGBT. 
TABLE 2: MSE result under different OC faults.

\begin{tabular}{|c|c|c|c|c|c|c|c|c|c|}
\hline \multirow{2}{*}{$\begin{array}{l}\text { Type } \\
\text { S1 }\end{array}$} & \multicolumn{3}{|c|}{$\mathbf{i}_{a}$} & \multicolumn{3}{|c|}{$\mathbf{i}_{b}$} & \multicolumn{3}{|c|}{$\mathbf{i}_{c}$} \\
\hline & 0.225 & 0.152 & 0.184 & 0.633 & 0.206 & 0.014 & 0.734 & 0.180 & 0.006 \\
\hline S2 & 0.189 & 0.208 & 0.188 & 0.078 & 0.220 & 0.110 & 0.416 & 0.170 & 0.004 \\
\hline S3 & 0.895 & 0.177 & 0.007 & 0.166 & 0.150 & 0.124 & 0.721 & 0.193 & 0.005 \\
\hline S4 & 0.839 & 0.174 & 0.007 & 0.166 & 0.165 & 0.170 & 0.410 & 0.159 & 0.177 \\
\hline S5 & 0.268 & 0.158 & 0.175 & 0.928 & 0.169 & 0.006 & 0.158 & 0.162 & 0.131 \\
\hline S6 & 0.678 & 0.213 & 0.014 & 0.993 & 0.177 & 0.009 & 0.149 & 0.136 & 0.159 \\
\hline S1 S2 & 0.173 & 0.156 & 0.350 & 0.111 & 0.193 & 0.002 & 0.421 & 0.187 & 0.003 \\
\hline S3 S4 & 0.735 & 0.197 & 0.006 & 0.176 & 0.151 & 0.028 & 0.413 & 0.199 & 0.006 \\
\hline S5 S6 & 0.400 & 0.202 & 0.007 & 0.778 & 0.207 & 0.013 & 0.120 & 0.191 & 0.136 \\
\hline S1 S3 & 0.507 & 0.186 & 0.209 & 0.287 & 0.113 & 0.142 & 0.731 & 0.183 & 0.009 \\
\hline S1 S5 & 0.367 & 0.100 & 0.177 & 0.777 & 0.167 & 0.008 & 0.536 & 0.150 & 0.135 \\
\hline S3 S5 & 0.713 & 0.169 & 0.004 & 0.497 & 0.135 & 0.168 & 0.214 & 0.113 & 0.176 \\
\hline S2 S4 & 0.910 & 0.239 & 0.209 & 0.174 & 0.102 & 0.195 & 0.436 & 0.185 & 0.009 \\
\hline S2 S6 & 0.394 & 0.144 & 0.145 & 0.131 & 0.178 & 0.011 & 0.204 & 0.130 & 0.212 \\
\hline S4 S6 & 0.803 & 0.195 & 0.008 & 0.509 & 0.160 & 0.170 & 0.332 & 0.098 & 0.193 \\
\hline S1 S4 & 0.699 & 0.194 & 0.195 & 0.273 & 0.170 & 0.177 & 0.417 & 0.197 & 0.011 \\
\hline S1 S6 & 0.331 & 0.164 & 0.184 & 0.374 & 0.188 & 0.003 & 0.752 & 0.192 & 0.180 \\
\hline S3 S2 & 0.514 & 0.212 & 0.174 & 0.254 & 0.113 & 0.177 & 0.495 & 0.176 & 0.008 \\
\hline S3 S6 & 0.268 & 0.192 & 0.005 & 0.548 & 0.206 & 0.169 & 0.266 & 0.126 & 0.185 \\
\hline
\end{tabular}

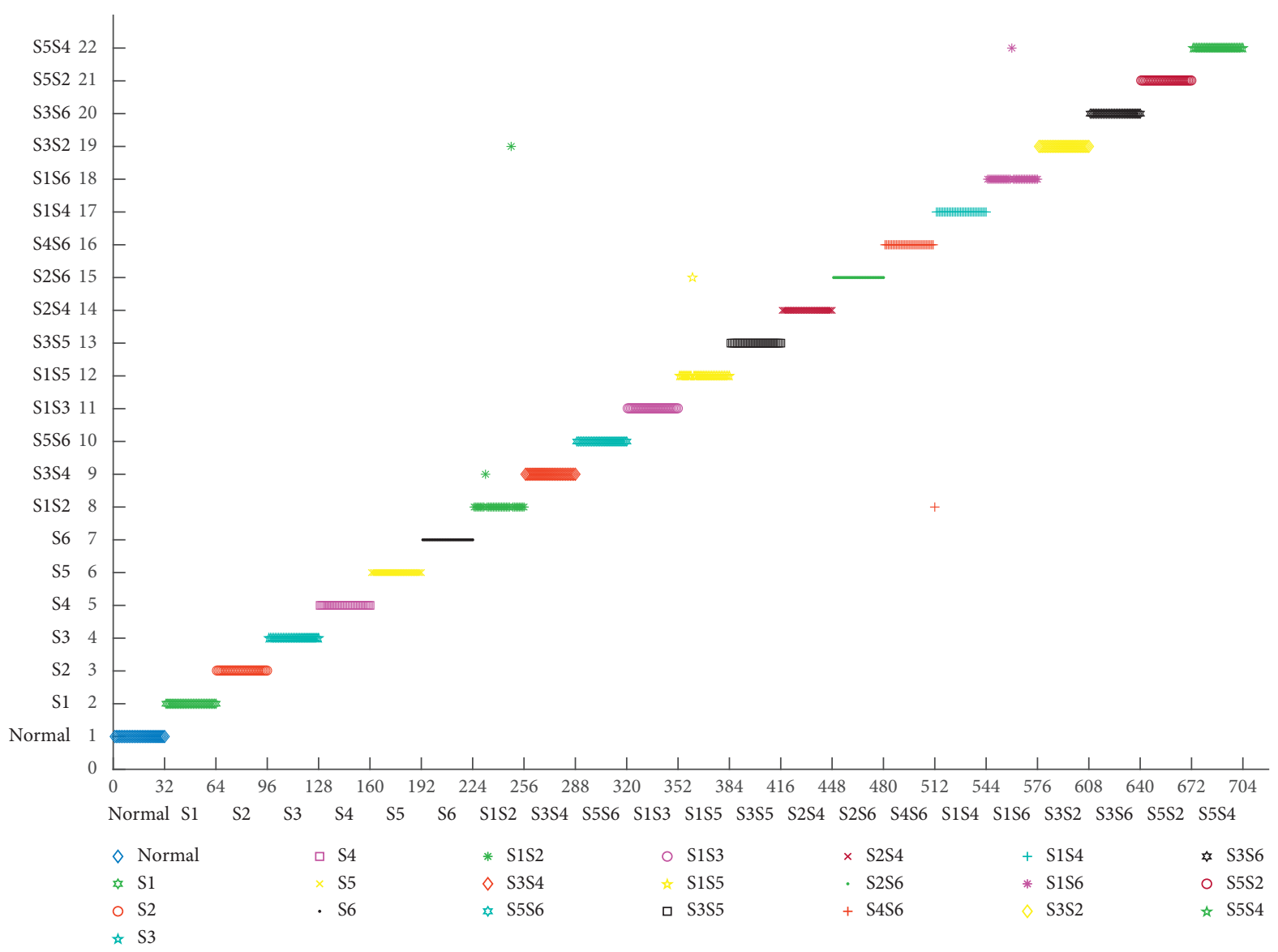

Figure 8: RSSVM result. 
TABle 3: Performance comparisons.

\begin{tabular}{lccccc}
\hline Method & Accuracy $(\%)$ & Diagnosis time $(s)$ & Method & Accuracy $(\%)$ & Diagnosis time $(s)$ \\
\hline RSSVM & 99.28 & 0.0129 & RNN & 94.968 & 0.0629 \\
MMNN & 98.27 & 0.0424 & FMNN & 96.72 & 0.0424 \\
TWSVM & 94.80 & 0.0722 & LSSVM & 92.80 & 0.0532 \\
CNN & 96.43 & 0.0457 & KSVCR & 93.43 & 0.0474 \\
\hline
\end{tabular}

\section{Simulation Result and Analysis}

The PSCAD environment is used to model and simulate the wind power generation systems OF PMSG. The main parameters of PMSG are shown in Table 1. Select OC faults occur in IGBT S1, S1, and S2 as typical faults. The LMD of the fault current are shown in Figures 5 and 6 . The threephase current information of fault features is mainly concentrated in the first three PF components.

The sample entropy in scale 1 to 6 of $P F_{1}$ component of the currenti $i_{a}$ when OC fault occurs in one IGBT is shown in Figure 7. The OC fault occurrence is similar to IGBT, and the sample entropy is different for different scales. The sample entropy at the same scale is also different for faults in different IGBT. Similarly, the conclusion is the same for the currents $\mathbf{i}_{\mathbf{b}}$ and $\mathbf{i}_{\mathbf{c}}$ and $P F_{2}$ and $P F_{3}$ components or even the OC fault occurrence in two IGBTs.

The MSE mean of the first three PF components of currents $\mathbf{i}_{a}, \mathbf{i}_{b}$, and $\mathbf{i}_{c}$ is calculated as the sample of RSSVM, as shown in Table 2. Each fault state has 100 samples: the first 68 samples are selected as the training set, and the last 32 sets of data are used as the testing sample. Figure 8 presents the classification result of the RSSVM results. This figure reveals that except for the testing samples S1S2, S1S5, S1S6, and S4S6, the diagnostic accuracy of all testing sample is $100 \%$. The final diagnostic accuracy for all 22 modes is $99.28 \%$. The diagnosis results show that the LMD-MSE fault diagnosis method has good performance for the OC fault diagnosis of the PMSG converter.

Numerical machine learning methods for fault diagnosis, such as Twin Support Vector Machines(TWSVM), Convolutional Neural Networks(CNN), Model Migration Neural Networks(MMNN) [46], and Least Squares Support Vector Machine(LSSVM) are given to make comparison. The results of comparison show that the SVM method used in this paper has the advantages in diagnostic accuracy and speed as depicted in Table 3.

\section{Conclusions}

This paper investigated OC fault converters in wind power generation systems with PMSG. A fault diagnosis strategy based on LMD and MSE is also proposed. The three-phase output current of converters is firstly processed by LMD, and the first three PF components of each current are obtained. Then, the MSE mean is calculated on the basis of statistical characteristics of the PFs, and the extracted LMD-MSE information is used to describe the diagnostic features. Finally, a novel multiclass SVM is applied in the proposed method. The results show that the method possesses a high self-adapt ability and avoids misjudgement or missed judgement. This method can provide a reference for engineers interested in this field.

\section{Data Availability}

The data used to support the findings of this study are available from the corresponding author upon request.

\section{Conflicts of Interest}

The authors declare that there are no conflicts of interest regarding the publication of this paper.

\section{Acknowledgments}

This research was funded by the National Natural Science Foundation of China (Grant nos. 61672226 and 61903137) and the Hunan Natural Science Foundation (Grant no. 2020JJ4316).

\section{References}

[1] K. Liu, C. Zou, K. Li, and T. Wik, "Charging pattern optimization for lithium-ion batteries with an electrothermalaging model," IEEE Transactions on Industrial Informatics, vol. 14, no. 12, pp. 5463-5474, 2018.

[2] Y. Shang, K. Liu, N. Cui, N. Wang, K. Li, and C. Zhang, "A compact resonant switched-capacitor heater for lithiumion battery self-heating at low temperatures," IEEE Transactions on Power Electronics, vol. 35, no. 7, pp. 7134-7144, 2019.

[3] K. Liu, Y. Shang, Q. Ouyang, and W. D. Widanage, “A datadriven approach with uncertainty quantification for predicting future capacities and remaining useful life of lithium-ion battery," IEEE Transactions on Industrial Electronics, 2020.

[4] K. Liu, X. Hu, Z. Wei, Y. Li, and Y. Jiang, "Modified Gaussian process regression models for cyclic capacity prediction of lithium-ion batteries," IEEE Transactions on Transportation Electrification, vol. 5, no. 4, pp. 1225-1236, 2019.

[5] S. Wang, J. Na, and Y. Xing, "Adaptive optimal parameter estimation and control of servo mechanisms: theory and experiments," IEEE Transactions on Industrial Electronics, p. 1, 2020.

[6] S. Wang and J. Na, "Parameter estimation and adaptive control for servo mechanisms with friction compensation," IEEE Transactions on Industrial Informatics, p. 1, 2020.

[7] S. Wang, L. Tao, Q. Chen, J. Na, and X. Ren, "USDE-based sliding mode control for servo mechanisms with unknown system dynamics," IEEE/ASME Transactions on Mechatronics, vol. 25, no. 2, pp. 1056-1066, 2020.

[8] Q. Chen, H. Shi, and M. Sun, "Echo state network-based backstepping adaptive iterative learning control for strictfeedback systems: an error-tracking approach," IEEE 
transactions on cybernetics, vol. 50, no. 7, pp. 3022-3009, 2019.

[9] Q. Chen, S. Xie, M. Sun, and X. He, "Adaptive nonsingular fixed-time attitude stabilization of uncertain spacecraft," IEEE Transactions on Aerospace and Electronic Systems, vol. 54, no. 6, pp. 2937-2950, 2018.

[10] M. Tao, Q. Chen, X. He, and M. Sun, "Adaptive fixed-time fault-tolerant control for rigid spacecraft using a double power reaching law," International Journal of Robust and Nonlinear Control, vol. 29, no. 12, pp. 4022-4040, 2019.

[11] J. Na, B. Wang, G. Li, S. Zhan, and W. He, "Nonlinear constrained optimal control of wave energy converters with adaptive dynamic programming," IEEE Transactions on Industrial Electronics, vol. 66, no. 10, pp. 7904-7915, 2018.

[12] J. Na, Y. Huang, X. Wu, S. F. Su, and G. Li, "Adaptive finitetime fuzzy control of nonlinear active suspension systems with input delay," IEEE Transactions on Cybernetics, vol. 50, no. 6, pp. 2639-2650, 2019.

[13] J. Na, A. S. Chen, Y. Huang et al., "Air-fuel ratio control of spark ignition engines with unknown system dynamics estimator: theory and experiments," IEEE Transactions on Control Systems Technology, pp. 1-8, 2019.

[14] N. R. Ullah, K. Bhattacharya, and T. Thiringer, "Wind farms as reactive power ancillary service providers-Technical and economic issues," IEEE Transactions on Energy Conversion, vol. 24, no. 3, pp. 661-672, Sep. 2009.

[15] R. S. Semken, M. Polikarpova, P. Röyttä et al., "Direct-drive permanent magnet generators for high-power wind turbines: benefits and limiting factors," IET Renewable Power Generation, vol. 6, no. 1, pp. 1-8, 2012.

[16] Y. Chen, P. Pillay, and A. Khan, "PM wind generator topologies," IEEE Transactions on Industry Applications, vol. 41, no. 6, pp. 1619-1626, 2005.

[17] H. Polinder, S. W. H. de Haan, M. R. Dubois, and J. G. Slootweg, "Basic operation principles and electrical conversion systems of wind turbines," Epe Journal, vol. 15, no. 4, pp. 43-50, 2005.

[18] G. Michalke, A. D. Hansen, and T. Hartkopf, "Control strategy of a variable speed wind turbine with multipole permanent magnet synchronous generator," European Wind Energy Conference and Exhibition, vol. 160, 2007.

[19] K. Tan and S. Islam, "Optimum control strategies in energy conversion of PMSG wind turbine system without mechanical sensors," IEEE Transactions on Energy Conversion, vol. 19, no. 2, pp. 392-399, 2004.

[20] F. Velenciaga and P. F. Puleston, "High-order sliding control for a wind energy conversion system based on a permanent magnet synchronous generator," IEEE Transactions and Energy Conversion, vol. 23, no. 3, pp. 860-867, 2008.

[21] V. Smet, F. Forest, J.-J. Huselstein et al., "Ageing and failure modes of IGBT modules in high-temperature power cycling," IEEE Transactions on Industrial Electronics, vol. 58, no. 10, pp. 4931-4941, 2011.

[22] S. Yang, A. T. Bryant, P. Mawby et al., "An industry-based survey of reliability in power electronic converters," IEEE Transactions on Industry Applications, vol. 47, no. 3, pp. 1441-1451, 2011.

[23] B. Jiang and Q. An, "A novel diagnostic technique for openswitch faults of inverters based on operating mode analysis," Proceedings of the CSEE, vol. 32, no. 24, pp. 30-37, 2012.

[24] B. Lu and K. S. Santosh, "A literature review of IGBT fault diagnostic and protection methods for power inverters," IEEE Trans on Industry Applications, vol. 45, no. 5, pp. 1770-1777, 2009.
[25] J. Liang, K. Zhang, A. Al-Durra, and D. Zhou, “A novel fault diagnostic method in power converters for wind power generation system," Applied Energy, vol. 266, p. 114851, 2020.

[26] Y. Shen, W. Zhou, Z. Ji, and T. Pan, "Fault identification of converter used in wind power generation based on wavelet packet analysis," Power System Technology, vol. 37, no. 7, pp. 2011-2017, 2013.

[27] S. Karimi, A. Gaillard, P. Poure, and S. Saadate, "FPGA-based real-time power converter failure diagnosis for wind energy conversion systems," IEEE Transactions on Industrial Electronics, vol. 55, no. 12, pp. 4299-4308, 2008.

[28] I. Jlassi, J. O. Estima, S. Khojet El Khil, N. Mrabet Bellaaj, and A. J. Marques Cardoso, "Multiple open-circuit faults diagnosis in back-to-back converters of pmsg drives for wind turbine systems," IEEE Transactions on Power Electronics, vol. 30, no. 5, pp. 2689-2702, 2015.

[29] J. .A. A. Caseiro, A. M. S. Mendes, and A. J. M. Cardoso, "Fault diagnosis on a PWM rectifier AC drive system with fault tolerance using the average current Park's Vector approach," in Proceedings of the IEEE International Electric Machines and Drives Conference, pp. 695-701, Miami, FL, USA, May 2009.

[30] K. Huang, J. Liu, S. Huang, Y. Yi, and L. Zhou, "Converters open-circuit fault-diagnosis method research for directdriven permanent wind power system," Transactions of China Electrotechnical Society, vol. 30, no. 16, pp. 129-136, 2015.

[31] Y. Tan, H. Zhang, and Y. Zhou, "A simple-to-implement fault diagnosis method for open switch fault in wind system PMSG drives without threshold setting," Energies, vol. 11, no. 10, p. 2571, 2018.

[32] N. M. A. Freire, J. O. Estima, and A. J. Marques Cardoso, "Open-circuit fault diagnosis in PMSG drives for wind turbine applications," IEEE Transactions on Industrial Electronics, vol. 60, no. 9, pp. 3957-3967, 2012.

[33] S. Abramik, W. Sleszynski, J. Nieznanski, and H. Piquet, "A diagnostic method for on-line fault detection and localization in VSI-fed AC drives," in Proceedings of the 10th. European Conference on Power Electronics and Applications, pp. 1-8, Toulouse, France, September 2003.

[34] J. Estima and A. J. M. Cardoso, "A new approach for real-time multiple open-circuit fault diagnosis in voltage source inverters," in Proceedings of the IEEE Energy Conversion Congress and Exposition, vol. 8, Atlanta, GA, USA, September 2010.

[35] S. Khomfoi, W. Sae-Kok, and I. Ngamroo, "An open circuit fault diagnostic technique in IGBTs for AC to DC converters applied in microgrid applications," Journal of Power Electronics, vol. 11, no. 6, pp. 801-810, 2011.

[36] M. Ren, Q. Zhang, and J. Zhang, "An introductory survey of probability density function control," Systems Science \& Control Engineering, vol. 7, no. 1, pp. 158-170, 2019.

[37] L. Yao, J. Qin J, H. Wang, and B. Jiang, "Design of new fault diagnosis and fault tolerant control scheme for non-Gaussian singular stochastic distribution systems," Automatica, vol. 48, no. 9, pp. 2305-2313, 2012.

[38] X. Yin, Q. Zhang, H. Wang, and Z. Ding, "Rbfnn-based minimum entropy filtering for a class of stochastic nonlinear systems," IEEE Transactions on Automatic Control, vol. 65, no. 1, pp. 376-381, 2019.

[39] D. Q. Dang, Y. Wang, and W. Cai, "Offset-free predictive control for variable speed wind turbines," IEEE Transactions on Sustainable Energy, vol. 4, no. 1, pp. 2-10, 2013.

[40] C. Zhe, J. Guerrero, and F. Blaabjerg, "A review of the state of the art of power electronics for wind turbines," IEEE 
Transactions Power Electronics, vol. 24, no. 8, pp. 1859-1875, 2009.

[41] A. Uehara, A. Pratap, T. Goya et al., "A coordinated control method to smooth wind power fluctuations of a PMSG-based WECS," IEEE Transactions on Energy Conversion, vol. 26, no. 2, pp. 550-558, 2011.

[42] H. H. H. Mousa, A.-R. Youssef, and E. E. M. Mohamed, "Variable step size P\&O MPPT algorithm for optimal power extraction of multi-phase PMSG based wind generation system," International Journal of Electrical Power \& Energy Systems, vol. 108, pp. 218-231, 2019.

[43] S.S Jonathan, "The local mean decomposition and its application to EEG perception data," Journal of The Royal Society Interface, vol. 2, no. 5, pp. 443-454, 2006.

[44] V. Vapnik, The Nature of Statistical Learning Theory, Springer science \& business media, Berlin, Germany, 2013.

[45] L. Tang, Y. Tian, and P. M. Pardalos, "A novel perspective on multiclass classification: regular simplex support vector machine," Information Sciences, vol. 480, pp. 324-338, 2019.

[46] X. Tang, K. Liu, X. Wang et al., "Model migration neural network for predicting battery aging trajectories," IEEE Transactions on Transportation Electrification, vol. 6, no. 2, pp. 363-374, 2020. 